\title{
Self-management practice, associated factors and its relationship with health literacy and patient activation among multi-morbid COPD patients from rural Nepal
}

Uday Narayan Yadav ${ }^{1,2^{*}}$ (D) Jane Lloyd ${ }^{1}$, Hassan Hosseinzadeh ${ }^{3}$, Kedar Prasad Baral $^{4}$, Narendra Bhatta ${ }^{5}$ and Mark Fort Harris ${ }^{1}$

\begin{abstract}
Background: Chronic Obstructive Pulmonary Disease (COPD) is a progressive and debilitating condition that affects individuals' quality of life. COPD self-management and supports provided by carers is key to the quality of life people living with COPD. Health literacy ( $\mathrm{HL})$ and Patient Activation (PA) are main drivers of self-management practices (SMPs). However, their contribution remains to be fully explored. This study aimed to examine the level of self-management practices, and the relationship with socio-demographic factors, $\mathrm{HL}$ and PA among multi-morbid COPD patients from rural Nepal.
\end{abstract}

Methods: This is a cross-sectional study conducted between July 2018 and January 2019. Patients completed a survey, including Self-management Practices questionnaire (SMPQ), five domains of the Health Literacy Questionnaire (HLQ), and Patient Activation Measure (PAM). The relationship between HL, PAM, and SMPs was examined using univariate statistics. Multivariable analysis was conducted to identify the factors associated with SMPs.

Results: A total of 238 patients responded to the study. The mean score of SMPQ was 45.31(SD = 9.00). The HLQ and PAM scores were positively correlated with the total score of SMPQ. Low level of SMPs were found to be positively associated with being uneducated ( $\beta=-0.43, p=.001$ ), having a low family income $(\beta=-5.22, p=.002)$, and, negatively associated with the presence of more than one co-morbidity $(\beta=3.58, p=0.007)$ after controlling for other socio-demographic variables in the multivariable analysis.

Conclusion: The overall SMPs among this sample of Nepalese with COPD were low. Our findings highlight the need to implement a self-management intervention program involving patient activation and health literacyfocused activities for COPD, creating a support system for patients from low-income families and low education.

Keywords: Health literacy, Multi-morbid Chronic Obstructive Pulmonary Disease (COPD), Patient activation, Selfmanagement practices

\footnotetext{
* Correspondence: u.yadav@unsw.edu.au; unyadav1@gmail.com

${ }^{1}$ Centre for Primary Health Care and Equity, UNSW, Sydney, Australia

${ }^{2}$ Forum for Health Research and Development, Dharan, Nepal

Full list of author information is available at the end of the article
}

(c) The Author(s). 2020 Open Access This article is licensed under a Creative Commons Attribution 4.0 International License, which permits use, sharing, adaptation, distribution and reproduction in any medium or format, as long as you give appropriate credit to the original author(s) and the source, provide a link to the Creative Commons licence, and indicate if changes were made. The images or other third party material in this article are included in the article's Creative Commons licence, unless indicated otherwise in a credit line to the material. If material is not included in the article's Creative Commons licence and your intended use is not permitted by statutory regulation or exceeds the permitted use, you will need to obtain permission directly from the copyright holder. To view a copy of this licence, visit http://creativecommons.org/licenses/by/4.0/ The Creative Commons Public Domain Dedication waiver (http://creativecommons.org/publicdomain/zero/1.0/) applies to the data made available in this article, unless otherwise stated in a credit line to the data. 


\section{Background}

Chronic Obstructive Pulmonary Disease (COPD) is a progressive and debilitating condition that impairs the quality of life of patients preventing participation in daily living activities because of progressively worsening symptoms. The presence of two or more other chronic conditions among COPD patients increases the severity of the condition, posing significant health challenges to patients' health and health systems [1]. The World Health Organisation (WHO) data shows the condition of COPD patients to be much worse in developing countries, where more than $90 \%$ of deaths occur because of lack of access to care and actionable strategies for prevention and management of COPD, than in developed countries [2]. A recent study from Nepal found a COPD prevalence of $11.7 \%$ highest among the list of selected non-communicable disease [3]. Despite the great understanding of the pathophysiology of disease and various advances in medicine, COPD remained as an incurable disease. This signifies the need of self-management practices (SMPs) that could play an important role in halting disease progression.

COPD self-management primarily involves self-recognition and management of symptoms, taking medication, having a healthy diet, coping with breathlessness, quitting smoking and engaging in regular physical exercise to maintain good health [4]. Evidence shows that various factors such as educational status [5-7], family history of COPD [6], lack of social support [8] and low socioeconomic status of family [9] are associated with poor SMPs.

Studies that supported patients in self-management have been found to be effective in improving quality of life in COPD patients and reducing hospital admissions $[4,10]$. Understanding and using health information to make health decisions [11] and patients being activated to manage their conditions [12], had a positive effect on self-management [13], and improved health outcomes [14-17]. A few studies have demonstrated the association between HL and PA with positive health outcomes $[18,19]$. Therefore, role of HL and PA is important in improving quality of life among COPD patients [13]. However, findings are not consistent, with two studies showing a correlation between both patient activation and health literacy [20] with SMPs [21]. However one study found no association between health literacy [22] and SMPs.

The "Right to Health" is stated in the Nepalese constitution [23] and the country has been able to achieve noticeable improvements during the era of Millennium Development Goals (MDGs). Government of Nepal, being a signatory of Sustainable Development Goals (SDGs) is committed in achieving SDGs 3 (sub-goal 3.4) aimed to "reduce one third premature mortality from non-communicable diseases through prevention and treatment with promotion of mental health and well- being" [24]. In this context, although some attention has been paid to SMPs of some chronic diseases such as Diabetes and Hypertension, there has been limited attention to the COPD self-management in Nepal. Therefore, the present study aimed to examine the level of SMPs, and the relationship with socio-demographic factors, HL and PA among multi-morbid COPD patients from rural Nepal.

\section{Methods}

\section{Setting and study design}

Participants were recruited via simple random sampling from the two rural municipalities of Sunsari district, Nepal. The study was carried out between July 2018 and January 2019. A random sampling approach was used to select the study participants from the list of 576 study samples obtained from two rural municipalities.

\section{Sample size}

The required sample size of 250 was determined based on following assumptions: prevalence (knowledge on selfmanagement $)=18 \%$, sampling error $=5.0 \%, C I=95.0 \%$, and non-response rate $=10.0 \%$. In line with the study protocol, 250 patients were selected randomly from the list of eligible subjects, but, only 238 patients met the eligibility criteria to participate.

To be eligible to participate, study participants had to fulfill the following criteria (i) aged between 18 and 70 years, (ii) diagnosed with COPD with at least one of the co-morbidities such as cardiovascular disease, diabetes, asthma, arthritis, depression, musculoskeletal disorders or gastritis (reflux) on their medical records; and (iii) able to provide consent form. Patients with a hearing disability, severe cognitive disorder, kidney disease, a history of stroke or diagnosed heart attack, and with a terminal illness such as cancer were excluded from the study.

\section{Measures}

Age, gender, ethnicity, education level, marital status, occupation, monthly family income, number of comorbidities, and self-reported history of alcohol and tobacco use were collected by administering a semistructured questionnaire.

\section{Self-management practices questionnaire (SMPQ)}

The 18-item SMPQ was adapted from the 51-item COPD Self-Management Scale (CSMS) [25] based on applicability and acceptability in the Nepalese context. Selected items measured information management, symptoms management, daily lifestyle management, emotional management, and self-efficacy. The responses to each item were graded on 5 -point scales where $1=$ never, 2 = rarely, $3=$ sometimes, $4=$ often, and $5=$ always. 


\section{Health literacy}

Five domains of the nine domain Health Literacy Questionnaire (HLQ) [26] were selected mainly due to their relevance to the local realities or context of Nepal. The domains included were: (i) feeling understood and supported by healthcare providers (HPS), (ii) having sufficient information to manage my own health (HIS), (iii) social support for health (SS), (iv) ability to find the good health information (AE), and (v) understand the health information well enough to know what to do (UHI) [27]. The responses to each item were graded on 5-point scales.

\section{Patient activation}

The shortened Nepali version of the PAM (13-item) was used to assess the self-reported knowledge, skill and confidence required for self-management of conditions [28]. PAM score ranges from 0 (no activation) to 100 (high activation) and are divided into four levels as follows: level 1, 0-47; level 2, 48-55; level 3, 56-66; level 4, 67-100 [29].

The English version of the questionnaires were first translated to Nepali and then translated back to English by two public health professionals who were fluent in both Nepali and English language to check the consistency. The Cronbach's $\alpha$ for SMPQ, HLQ, and PA was above 0.7 , indicating good internal consistency.

\section{Data collection procedure}

Interviewer-administered data collection was conducted over 3 months, where data was filled in Nepali questionnaires. The data collection was performed by trained research assistants who were fluent in both Maithili (a local language spoken by chunks in a rural setting) and a Nepali language. Two-day' hands-on training was provided to the research assistants by the principal investigator of this study group. The principal investigator monitored the entire field activities to ensure data quality and updates were shared with the research team on weekly basis.

\section{Statistical analyses}

Data were analysed using SPSS version 25. Sample characteristics were summarised as frequency and percentage for discrete variables and as means and standard deviation for a continuous variable. Multivariate linear regression analysis was used carried out to identify the factors associated with a low level of self-management practices. Similarly, Spearman's correlations were carried out to test the relationships of five domains of the HLQ and PAM with self-management practices.

\section{Results}

\section{Subject characteristics}

The characteristics of the study participants are shown in Table 1. Among 238 participants, 55\% were women,
Table 1 Sample characteristics

\begin{tabular}{|c|c|c|}
\hline Characteristics & $\mathrm{n}$ & $\%$ \\
\hline \multicolumn{3}{|l|}{ Gender } \\
\hline Male & 107 & 45 \\
\hline Female & 131 & 55 \\
\hline \multicolumn{3}{|l|}{ Age category (years) } \\
\hline$\leq 40$ & 18 & 7.6 \\
\hline $41-55$ & 44 & 18.5 \\
\hline$\geq 56$ & 176 & 73.9 \\
\hline \multicolumn{3}{|l|}{ Education status } \\
\hline uneducated & 166 & 69.7 \\
\hline educated & 72 & 30.3 \\
\hline \multicolumn{3}{|l|}{ Marital status } \\
\hline Married & 176 & 73.9 \\
\hline Unmarried/divorced/widow/widower & 62 & 26.1 \\
\hline \multicolumn{3}{|l|}{ Ethnicity } \\
\hline Brahmin/Chhetri (Higher caste) & 98 & 41.2 \\
\hline Indigenous (Adivasi Janajati) & 91 & 38.2 \\
\hline $\begin{array}{l}\text { Dalits (untouchable caste as per traditional Hindu } \\
\text { caste system) }\end{array}$ & 49 & 20.6 \\
\hline \multicolumn{3}{|l|}{ Religion } \\
\hline Hindu & 222 & 93.3 \\
\hline Islam & 16 & 6.7 \\
\hline \multicolumn{3}{|l|}{ Occupation } \\
\hline Farmer/Housewife & 108 & 45.4 \\
\hline $\begin{array}{l}\text { Professional jobs (Business/government jobs/private } \\
\text { company) }\end{array}$ & 8 & 3.4 \\
\hline Factory workers/labourers & 122 & 51.3 \\
\hline \multicolumn{3}{|l|}{ Family income level (NRs) } \\
\hline$\leq 20,000$ & 206 & 86.6 \\
\hline$>20,000$ & 32 & 13.4 \\
\hline \multicolumn{3}{|l|}{ Use of tobacco product } \\
\hline No & 45 & 18.9 \\
\hline Yes & 193 & 81.1 \\
\hline \multicolumn{3}{|l|}{ Comorbidities } \\
\hline At least one $e^{a}$ & 60 & 25.2 \\
\hline Two or more & 178 & 74.8 \\
\hline
\end{tabular}

with a mean age of 59.18 years $(S D=12.19)$. Most of the participants were uneducated (69.7\%) and married (73.9\%). Similarly, most participants belonged to higher (Brahmin/Chhetri) caste (41.2\%), followed by indigenous (38.2\%) and Dalit (20.6\%). Most reported Hinduism to be their religion (93.3\%). More than half of the study participants were employed as factory workers/laborers. Over $70.0 \%$ of the study participants reported a monthly 
family income of less than NRs. 20,000, (176 USD). More than $80 \%$ of the participants were current or past tobacco users. Most of the participants reported the presence of two or more co-morbidities (74.8\%).

\section{Relationship between self-management practices, $\mathrm{HL}$ and} PA

The mean SMPs score was 45.31(SD = 9.00).

All five of the domains of HL and the PAM score were found to be moderately correlated with a total score of SMPs (Table 2).

\section{Factors associated with poor SMPs}

As shown in Table 3, low levels of SMPs were associated with being uneducated $(\beta=-0.43, p=.001)$, having a low of family income $(\beta=-5.22, p=.002)$, and negatively associated with the presence of more than one co-morbidity $(\beta=3.58, p=0.007)$ of after controlling for socio-demographic variables in the multivariable analysis.

\section{Discussion}

The objective of this study was to address important gaps in the literature by investigating the level of SMPs, and their relationship with socio-demographic factors, $\mathrm{HL}$ and PA among multi-morbid COPD patients from rural Nepal. To our knowledge, this is the first study assessing the level the SMPs among multi-morbid COPD patients living in the rural areas of Nepal.

Our findings showed that participants' SMPs were very limited. This level was very low compared to studies from China [30], USA [31] and Norway [32]. It is possible that this difference could be due to the difference in the instruments used to measure self-management practices. In this light, a hospital-based study from Nepal reported that $90.7 \%$ of COPD patients had a poor level of knowledge on the self-care of COPD [6]. In Nepal, the majority of the COPD patients seek services from the government or private hospitals because of the

Table 2 Correlation of HL domains, PAM with total score of SMPs among multi-morbid COPD patients

\begin{tabular}{llll}
\hline Variables & Mean \pm SD & Spearman's correlation & $p$-value \\
\hline PAM & $34.18 \pm 14.20$ & .367 & $<0.001$ \\
HLQ domains & & & \\
HPS & $1.96 \pm .76$ & .528 & $<0.001$ \\
HSI & $1.56 \pm .74$ & .433 & $<0.001$ \\
SS & $2.73 \pm .77$ & .393 & $<0.001$ \\
AE & $2.02 \pm 1.10$ & .406 & $<0.001$ \\
UHI & $1.78 \pm .99$ & .354 & $<0.001$
\end{tabular}

HPS Feeling understood and supported by healthcare providers, HIS Having sufficient information to manage my own health, SS Social support for health, $A E$ Ability to find the good health information, $U H I$ understand the health information well enough to know what to do inadequacy of available services at the primary health care level. The underlying reason for poor selfmanagement includes both practitioner and patientrelated factors. For example, practitioners in Nepal focus more on prescribing the medicines and less on supporting the development of self-management skills in the patients. In contrast, patients may not have accepted information provided by practitioners that conflicts with their own beliefs (a belief that medicines are always more effective than of lifestyle change).

In our study, the five domains of HLQ and the PAM were all found to be moderately correlated with a total score for SMPs. No previous studies have assessed the association of HL and PAM with SMPs in patients with COPD. However, studies focusing on other chronic disease have assessed these associations. In contrast to our results, a study conducted by Jacobson et al. [33] among patients with heart failure showed that self-management behaviours' were associated with patient activation but not with health literacy. The findings of our current study are consistent with early studies that separately demonstrated a positive association between both PAM $[14,19,33]$ and HL $[19,34]$ with self-management of behaviours. A possible reason for inconsistent results may be that different HL measures, study population and setting used in these studies.

However, neither HL nor PA is static concepts, and the finding across the studies could vary because of difference in levels of HL, health system structure, levels of understanding of their conditions and motivation to self-manage their conditions. There is a growing body of evidence showing that PA and HL are independent concepts $[13,35]$. Our data confirmed that both low $\mathrm{HL}$ and PA were associated with inadequate engagement in SMPs.

In this community-based study, we identified that being uneducated, with a low level of family income $(\beta=-5.22$, $p=.002)$, and having one co-morbidity were all significantly associated with SMPs among the multi-morbid COPD patients of Nepal. Our finding is consistent with observations from a previous Nepalese study that concluded lack of education among the COPD patients contributed to poor SMPs such as incorrect use of inhalers [5], knowledge on self-care [6] and knowledge on COPD [7]. Patients with no education have poor functional health literacy and thus are more likely to have a poorer understanding of self-management skills including information management, symptoms management, daily lifestyle management, emotional management, and selfefficacy, in turn resulting in poor SMPs. In our study, a low level of family income was associated with poor SMPs which is supported by the findings of a review [36] that identified low-socioeconomic status as a determinant for self-management of behaviours. 
Table 3 Associates of poor SMPs among multi-morbid COPD patients of Nepal

\begin{tabular}{|c|c|c|c|c|}
\hline Variables & Unstandardized $\beta$ & Standardised $\beta$ & Confidence Interval (Cl) & $\boldsymbol{P}$-value \\
\hline \multicolumn{5}{|l|}{ Gender } \\
\hline Male & Reference & Reference & & \\
\hline Female & 0.05 & 0.003 & -2.45 to 2.55 & .96 \\
\hline \multicolumn{5}{|l|}{ Education status } \\
\hline Educated & Reference & Reference & & \\
\hline Uneducated & -0.43 & -0.22 & -.7 .11 to -1.75 & .001 \\
\hline \multicolumn{5}{|l|}{ Age group(years) } \\
\hline$\leq 40$ & Reference & Reference & & \\
\hline $41-55$ & 1.23 & 0.05 & -3.74 to 6.20 & .62 \\
\hline$\geq 56$ & 2.36 & 0.11 & -2.59 to 7.32 & .34 \\
\hline \multicolumn{5}{|l|}{ Marital status } \\
\hline Married & Reference & Reference & & \\
\hline Unmarried/Divorce/Widow/widower & -0.33 & -.01 & -3.03 to 2.37 & .80 \\
\hline \multicolumn{5}{|l|}{ Ethnicity } \\
\hline Higher caste & Reference & Reference & & \\
\hline Indigenous & -0.06 & -0.004 & -2.54 to 2.41 & .95 \\
\hline Dalits (Untouchable as per traditional Hindu caste system) & -.44 & -.02 & -3.49 to 2.60 & .77 \\
\hline \multicolumn{5}{|l|}{ Occupation } \\
\hline Farmer/housewife & Reference & Reference & & \\
\hline Professional jobs (Govt, Private, Businessman) & .97 & .02 & -5.40 to 7.36 & .76 \\
\hline Factory workers/labourers & -1.66 & -0.9 & -4.08 to .76 & .17 \\
\hline \multicolumn{5}{|l|}{ Family income level (NRs)\# } \\
\hline$<20,000$ & -5.22 & -.19 & -8.48 to -1.96 & .002 \\
\hline$>20,001$ & Reference & Reference & & \\
\hline \multicolumn{5}{|l|}{ Use of tobacco products } \\
\hline No & Reference & Reference & & \\
\hline Yes & -0.97 & -.04 & -4.30 to 2.35 & .56 \\
\hline \multicolumn{5}{|l|}{ Presence of chronic illness by comorbidities } \\
\hline At least one ${ }^{a}$ & Reference & Reference & & \\
\hline More than two ${ }^{b}$ & 3.58 & .17 & .99 to 6.16 & .007 \\
\hline
\end{tabular}

Our research found a negative association between low-level SMPs and the presence of more than one comorbidity. In contrast, a study conducted by Bringsvor et al. focusing on COPD patients that showed that the presence of co-morbidities was associated with poor self-management practices [32]. No previous research has identified an association between higher levels of SMPs with a higher number of co-morbidities. In our context, one possible explanation could be that patients being suffering from multiple morbidities may have acquired motivation and generic knowledge and self-skills that they have been able to apply across a range of conditions (e.g., physical activity, smoking cessation etc.).
Moreover, patients' having more than one co-morbidity may have sought more information on the disease and available health services using various social networks including family members, friends, relatives, school teachers, etc. A framework for health literacy and health actions developed by Wagner et al. [37] described the motivational pathway arising from the interaction between health literacy and established social cognitive variables such as health-related knowledge, attitudes, or beliefs and the decision to use primary health care and to self-manage the conditions.

Strengths of this study include a high response rate (95\%), and quality of data was maintained by collecting 
data with the help of trained enumerators who spoke the local languages (Maithili/Tharu/Thet Maithili) of most of those in the communities studied. Limitations of the study included its cross-sectional design; which preclude definition of the cause-effect relationships. The study enrolled participants from only two rural municipalities in one district in Nepal. Thus the results may not be generalizable to a wider population and other geographical areas of Nepal. Additionally, we used self-reported questionnaires that could have some socio-desirability bias. Due to our funding constraints, we could not perform confirmatory diagnosis; instead, we selected the patients based on the patient's medical history obtained from PHC or by looking into patients' medical record history in the community setting.

Our study revealed a relationship between HL, PA, and other socio-demographic variables with SMPs. Good SMPs among multi-morbid COPD patients may be achieved by improving the skills of the health care professionals who deal with COPD and other chronic conditions in tailoring patient education to their health literacy levels and seeking to engage patients more actively in their care. Assessment of HL and PA in the clinical setting may help health care professionals to plan self-management support. Self-management being an effective paradigm in the prevention spectrum, delivering activities to address the medical, psychological and life style needs of patients via an integrated multi-level approach (individual, family, community and system) could be more beneficial to improve self-management behaviours. In this regard, we emphasize the need to design and implement self-management program by addressing the gaps identified by our study for improving the quality of life of patients. Furthermore, this research has opened the door for researchers who are interested in analyzing the concept of $\mathrm{HL}$ and PA and its incorporation in behaviour change interventions to improve SMPs and the quality of life among COPD patients and other chronic diseases.

\section{Conclusion}

In conclusion, this study provided insights into SMPs among the multi-morbid COPD patients in a rural setting of Nepal. The findings showed that being uneducated, having a low of family income, low scores in HL and PAM are important associates that impede the SMPs in COPD patients. These findings highlight the necessity of crafting and implementing COPD selfmanagement programs which enhance patient activation and health literacy, creating a support system for patients from low-income and low education attainment.

\section{Abbreviations}

AE: Ability to find the good health information; COPD: Chronic Obstructive Pulmonary Disease; HIS: Having sufficient information to manage my own health; HL: Health Literacy; HLQ: Health Literacy Questionnaire; HPS: Feeling understood and supported by healthcare providers; HREC: Human Research Ethics Committee (HREC); PA: Patient Activation; PAM: Patient Activation Measure; SMPQ: Self-management practices questionnaire; SMPs: Selfmanagement practices; SS: Social support for health; UHI: Understand the health information well enough to know what to do; UNSW: University of New South Wales

\section{Acknowledgments}

We want to thank the local-level authorities of the government of Nepal for their support in providing us with the list of COPD patients. The authors like to thank, more respectfully to Mr. Gajendra Yadav (Health Co-ordinator of Gadhi Rural Municipality), Mr. Dinesh Chaudhary (Barju Rural Municipality) for providing the support in reaching the patients and, Mr. Krishna Yadav and Nitesh Mandal for their tireless work in recruitment and data collection. The COPD patients who participated in the study are also gratefully acknowledged without which this study would not have been successful. UNY is receipt of University International Postgraduate Scholarship and CPHCE Top-up Scholarship for pursuing Ph.D.

\section{Authors' contributions}

UNY conceived and conducted the fieldwork and wrote the first version of this manuscript as a Ph.D. student under the supervision of MFH, JL, HH, KPB, and NB. All authors participated in the data analysis as well as read and gave their approval to the final version of this manuscript submitted for publication.

\section{Funding}

This fieldwork was supported by the Medibank International Fieldwork Grant and funding body had no role in the study.

Availability of data and materials

Data is available on request from the corresponding author.

\section{Ethics approval and consent to participate}

Ethics approval was obtained from Human Research Ethics Committee (HREC) of University of New South Wales (UNSW), Sydney, Australia (HC180502), and the Nepal Health Research Council (Reg no 495). All the participants completed and signed an informed consent form.

\section{Consent for publication}

Not applicable.

\section{Competing interests}

The authors declare that they have no competing interests.

\section{Author details}

${ }^{1}$ Centre for Primary Health Care and Equity, UNSW, Sydney, Australia. ${ }^{2}$ Forum for Health Research and Development, Dharan, Nepal. ${ }^{3}$ The University of Wollongong, Sydney, Australia. ${ }^{4}$ School of Public Health, Patan Academy of Health Sciences, Kathmandu, Nepal. ${ }^{5}$ Department of Pulmonary, Critical Care and Sleep Medicine, B.P. Koirala Institute of Health Sciences (BPKIHS), Dharan, Nepal.

Received: 19 September 2019 Accepted: 25 February 2020

Published online: 06 March 2020

\section{References}

1. Holland AE, Harrison SL, Brooks D. Multimorbidity, frailty and chronic obstructive pulmonary disease: are the challenges for pulmonary rehabilitation in the name? Chronic Respiratory Diesease. 2016;13(4):372-82.

2. WHO. Chronic respiratory diseases. Chronic obstructive pulmonary disease (COPD). Geneva: Switzerland: World Health Organization; 2019.

3. Thapa N, Maharjan M, Shrestha TM, Gauchan S, Pun P, Thapa YB. Anxiety and depression among patients with chronic obstructive pulmonary disease and general population in rural Nepal. BMC Psychiatry. 2017;17:397.

4. Zwerink M, Brusse-Keizer M, Pvd V, Zielhuis G, Monninkhof E, Jvd P, et al. Self management for patients with chronic obstructive pulmonary disease. Cochrane Database Syst Rev. 2014;19(3):CD002990. 
5. Baral MA. Knowledge and practice of dry powder inhalation among patients with chronic obstructive pulmonary disease in a regional hospital. Nepal Int J Gen Med. 2019;12:31-7.

6. HK Subba RS. Knowledge on self care among copd patients attending at Chitwan medical college, teaching hospital, Bharatpur. J Chitwan Med College. 2014:4(8):4.

7. Shrestha ASS, Khanal VK, Bhattarai S, Maskey R, Pokharel PK. Health Literacy and Knowledge of Chronic Diseases in Nepal. Health Lit Res Pract. 2(4):e221.

8. Chen Z, Fan VS, Belza B, Pike K, Nguyen HQ. Association between social support and self-care behaviors in adults with chronic obstructive pulmonary disease. Ann Am Thorac Soc. 2017;14(9):1419-27.

9. Disler RT, Gallagher RD, Davidson PM. Factors influencing self-management in chronic obstructive pulmonary disease: an integrative review. Int J Nurs Stud. 2012;49(2):230-42.

10. Lenferink A, Brusse-Keizer M, van der Valk PD, Frith PA, Zwerink M, Monninkhof EM, et al. Self-management interventions including action plans for exacerbations versus usual care in patients with chronic obstructive pulmonary disease. Cochrane Database Syst Rev. 2017;8: Cd011682.

11. WHO. Health Promotion. Track 2: Health literacy and health behaviour Geneva: Switzerland: World Health Organization; 2019 [Available from: https://www.who.int/healthpromotion/conferences/7gchp/track2/en/.

12. Greene J, Hibbard J, Hibbard H. Why does patient activation matter? An examination of the relationships between patient activation and healthrelated outcomes. Gen Intern Med. 2012;27(5):520-6.

13. Yadav UN, Hosseinzadeh H, Lloyd J, Harris MF. How health literacy and patient activation play their own unique role in self-management of chronic obstructive pulmonary disease (COPD)? Chronic Respir Dis. 2018;16: 1479973118816418.

14. Shively M, Gardetto N, Kodiath M, Kelly A, Smith T, Stepnowsky C, et al. Effect of patient activation on self-management in patients with heart failure. J Cardiovasc Nurs. 2013 Jan-Feb;28(1):20-34.

15. Wang T, Tan J, Xiao L. Effectiveness of disease-specific self-management education on health outcomes in patients with chronic obstructive pulmonary disease: an updated systematic review and meta-analysis. Patient Educ Couns. 2017:100(8):1432-46.

16. Yadav U, Hosseinzadeh H, Baral K. Self-management and patient activation in COPD patients: an evidence summary of randomized controlled trials. Clin Epidemiol Global Health. 2017;6(3):148-54.

17. Jayasinghe $U$, Harris M, Parker S, Litt J, Mv D, Mazza D, et al. The impact of health literacy and life style risk factors on health-related quality of life of Australian patients. Health Qual Life Outcomes. 2016;14:68.

18. Gwynn K, Winter M, Cabral H, Wolf M, Hanchate A, Henault L, et al. Racial disparities in patient activation: evaluating the mediating role of health literacy with path analyses. Patient Educ Couns. 2016;99(6):1033-7.

19. Smith S, Curtis L, Wardle J, Wagner CV, Wolf M. Skill set or mind set? Associations between health literacy, patient activation and health. PLoS One. 2013 Sep 4;8(9):e74373.

20. Dunlay S, Griffin J, Redfield M, Roger V. Patient Activation in Acute Decompensated Heart Failure. J Cardiovasc Nurs. 2017 Nov/Dec;32(6):560-7.

21. Masterson R, Chen T, Wei C, Lee C. Brief report: patient activation among urban hospitalized patients with heart failure. J Card Fail. 2017 Nov;23(11): 817-20.

22. Jacobson AF, Sumodi V. M. Albert N, S. Butler R, DeJohn L, Walker D, et al. patient activation, knowledge, and health literacy association with selfmanagement behaviors in persons with heart failure. Heart Lung. Sep-Oct 2018;47(5):447-51.

23. Baral GBK. Yadav UN. Accelerating Progress towards Reaching Sustainable Development Goals. 2018;12(1):5-7.

24. Government of Nepal NPC. Sustainable Development Goals 2016-2030, National (preliminary) report. Government of Nepal, National Planning Commission, Kathmandu, Nepal 2016

25. Zhang C, Wang W, Li J, Cai X, Zhang H, Wang H, et al. Development and validation of a COPD self-management scale. Respir Care. 2013:58(11):1931-6.

26. Osborne RH, Batterham RW, Elsworth GR, Hawkins M, Buchbinder R. The grounded psychometric development and initial validation of the health literacy questionnaire (HLQ). BMC Public Health. 2013;13(1):658.

27. Spooner C, Jayasinghe UW, Faruqi N, Stocks N, Harris MF. Predictors of weight stigma experienced by middle-older aged, general-practice patients with obesity in disadvantaged areas of Australia: a cross-sectional study. BMC Public Health. 2018;18(1):640.
28. Insigniahealth. PAM Survey: Insigniahealth; [Available from: https://www insigniahealth.com/products/pam-survey.

29. Hibbard JH, Greene J, Overton V. Patients With Lower Activation Associated With Higher Costs; Delivery Systems Should Know Their Patients' 'Scores'. Health Aff. 2013;32(2):216.

30. Yang $H$, Wang $H$, Du L, Wang $Y$, Wang $X$, Zhang R. Disease knowledge and self-management behavior of COPD patients in China. Medicine (Baltimore). 2019;98(8):e14460.

31. Benzo RP, Abascal-Bolado B, Dulohery MM. Self-management and quality of life in chronic obstructive pulmonary disease (COPD): the mediating effects of positive affect. Patient Educ Couns. 2016;99(4):617-23.

32. Bringsvor HB, Skaug K, Langeland E, Oftedal BF, Assmus J, Gundersen D, et al. Symptom burden and self-management in persons with chronic obstructive pulmonary disease. Int J Chron Obstruct Pulmon Dis. 2018;13: 365-73.

33. Jacobson AF, Sumodi V, Albert NM, Butler RS, DeJohn L, Walker D, et al. Patient activation, knowledge, and health literacy association with selfmanagement behaviors in persons with heart failure. Heart Lung. 2018; 47(5):447-51.

34. Geboers B, de Winter AF, Spoorenberg SL, Wynia K, Reijneveld SA. The association between health literacy and self-management abilities in adults aged 75 and older, and its moderators. Qual Life Res. 2016:25(11):2869-77.

35. Couture EM, Chouinard MC, Fortin M, Hudon C. The relationship between health literacy and patient activation among frequent users of healthcare services: a cross-sectional study. BMC Fam Pract. 2018;19(1):38.

36. Pampel FC, Krueger PM, Denney JT. Socioeconomic disparities in health behaviors. Annu Rev Sociol. 2010;36:349-70

37. von Wagner C, Steptoe A, Wolf MS, Wardle J. Health literacy and health actions: a review and a framework from health psychology. Health Educ Behav. 2009;36(5):860-77.

\section{Publisher's Note}

Springer Nature remains neutral with regard to jurisdictional claims in published maps and institutional affiliations.
Ready to submit your research? Choose BMC and benefit from:

- fast, convenient online submission

- thorough peer review by experienced researchers in your field

- rapid publication on acceptance

- support for research data, including large and complex data types

- gold Open Access which fosters wider collaboration and increased citations

- maximum visibility for your research: over $100 \mathrm{M}$ website views per year

At $\mathrm{BMC}$, research is always in progress.

Learn more biomedcentral.com/submissions 